\title{
二次性大動脈腸管瘻に対するステントグラフト内揮術
}

$$
\begin{array}{llllllllll}
\text { 衛 } & \text { 藤 } & \text { 弘 } & \text { 城* } & \text { 吉 } & \text { 鷹 } & \text { 秀 } & \text { 範 } & \text { 都津川 敏範 } & \text { 杭 瀬昌彦 } \\
\text { 津 } & \text { 島 } & \text { 義 } & \text { 正 } & \text { 石 } & \text { 田 } & \text { 敦 } & \text { 久 } & \text { 近 沢 元 太 } & \text { 平 岡 有 努 }
\end{array}
$$

症例は 76 歳男性. 18 年前に腹部大動脈瘤に対して腹部大動脈人工血管置換術を施行されていた. 2008 年腹 部大動脈中枢側吻合部仮性瘤を原因とする二次性大動脈腸管瘻 (secondary aortoenteric fistula : SAEF) のため当院搬送となり，出血性ショック状態のため緊急でステントグラフト内挿術 (endovascular aneurysmal repair ; EVAR）を行った。術翌日に瘻孔部を縫合閉鎖し，空腸瘻も造設した。術後感染徵候なく第 34 病日に独歩退院となった。その後感染徵候なく経過していたが，術後 16 カ月目に突然の吐血を認めた. SAEF 再発にて膵頭十二指腸切除術を行ったが, 術前からの敗血症が原因で第 11 病日に死亡した. SAEF 急性期における出血コントロールに EVAR は有用であるが，遠隔期死亡を回避するために，全身状態の安 定が得られしだい，開腹手術による根治を目指す必要があると考えられた．日心外会誌 41 巻 5 号 : 270-275 (2012)

$$
\text { キーワード：二次性大動脈腸管瘻, ステントグラフト内挿術, グラフト感染, 吻合部仮性動脈瘤 }
$$

\section{Endovascular Aneurysmal Repair for an Aortoenteric Fistula}

Koki Eto*, Hidenori Yoshitaka, Toshinori Totsugawa, Masahiko Kuinose, Yoshimasa Tsushima, Atsuhisa Ishida, Genta Chikazawa and Arudo Hiraoka (Department of Cardiovascular Surgery, The Sakakibara Heart Institute of Okayama, Okayama, Japan, Present address : Department of Metabolic Disorder, Research Institute, National Center for Global Health and Medicine*, Tokyo, Japan)

We report a case of secondary aortoenteric fistula (SAEF). A 76-year-old man who had undergone bifurcated graft replacement for an abdominal aortic aneurysm 18 years previously was admitted to our hospital on 2008. Since the patient was in hemorrhagic shock and had several comorbidities, he first underwent emergency endovascular aneurysmal repair (EVAR). The patient recovered from shock, and then the duodenal fistula was closed and a temporary tube enterostomy was made on the next day. The patient's recovery was uneventful and he was discharged 34 days after EVAR without any sign of infection. However, the patient was admitted for a recurrent SAEF 16 months after the procedure. Although emergency surgery was performed, he died due to sepsis 11 days after surgery. EVAR could be useful to control bleeding associated with SAEF ; however, it would be necessary for a long-term results to perform additional radical surgery subsequently to ensure the patients' hemodynamic recovery. Jpn. J. Cardiovasc. Surg. $41: 270-275$ (2012)

Keywords : secondary aortoenteric fistula, endovascular aneurysmal repair, graft infection, pseudoaneurysm

二次性大動脈腸管瘻 (secondary aortoenteric fistula: SAEF）は，消化管出血や人工血管感染のため重症化する 症例が多く，外科的治療でも救命が困難な疾患である. 1997 年, SAEF に対してステントグラフトを用いた最初の 治療例が報告され, 以来開腹手術が困難な最重症例を中心 に報告が散見されるようになった，今回われわれは，腹部 大動脈瘤 $(\mathrm{AAA})$ 術後 18 年目に SAEF を発症し, SAEF に対してステントグラフト内挿術（endovascular aneurys-

2011 年 11 月 21 日受付, 2012 年 6 月 4 日採用

Corresponding author: Koki Eto

心臟病センター榊原病院心臟血管外科

₹ 700-0823 岡山市北区丸の内 2-1-10

*現 国立国際医療研究センター研究所代謝疾患研究部

于 162-8655 東京都新宿区戸山 1-21-1 mal repair ; EVAR) にて治療を行った 1 例を経験した. SAEF に対するEVAR を含めた治療戦略について, 文献的 考察を含めて報告する.

\section{症例}

症例 : 76 歳, 男性.

主訴 : 腹痛, 吐血, 意識障害.

既往歴：1990 年, 腎動脈下腹部大動脈瘤に対して腹部 大動脈人工血管置換術 (他院). 1996 年, 肺癌にて右肺上 葉切除術.

家族歴：特記事項なし。

現病歴: 2008 年, 突然の腹痛の直後に吐血と意識障害 をきたし, 近医に救急搬送された。腹部 CT 検査にて SAEFが疑われ，手術目的に当院転送となった。 


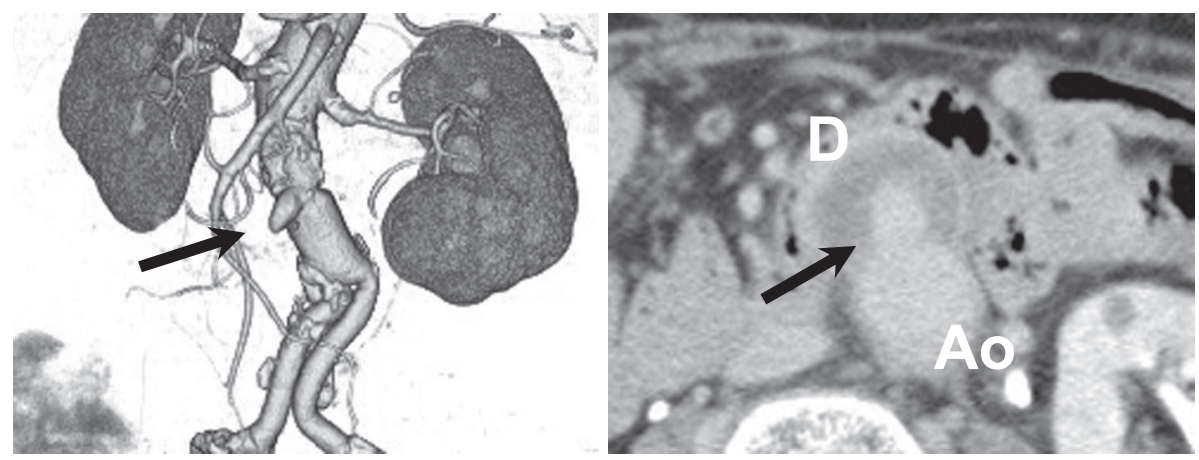

図 1 SAEF 発症時 CT

腹部人工血管置換術後の中枢側吻合部腹側において, 十二指腸内腔へ突出する仮性瘤を 認める (矢印). Ao : aorta, D : duodenum.
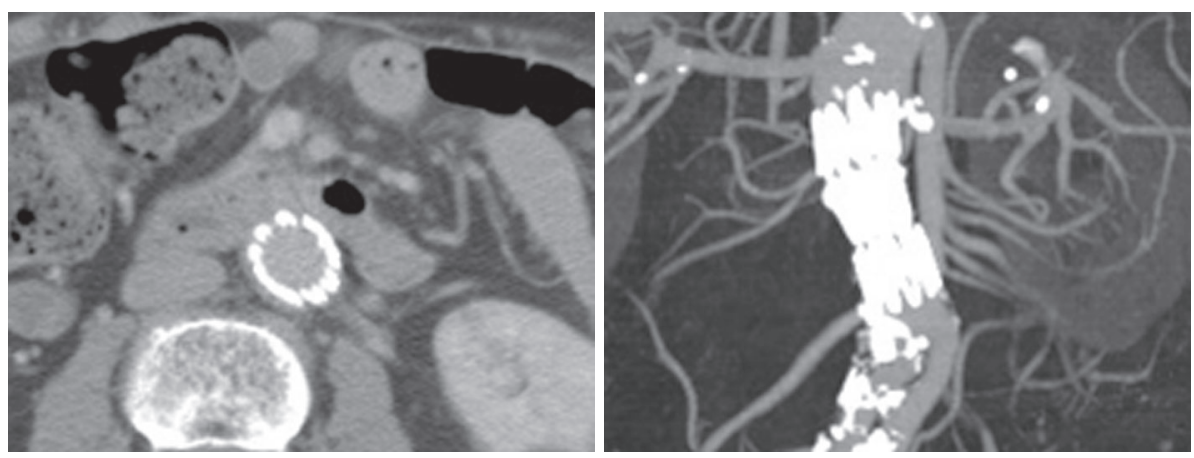

図 2 ステントグラフト内挿術後 CT

仮性瘤は消失し腸管内への造影剂漏出も認めない.

入院時現症：身長 $164 \mathrm{~cm}$, 体重 $55 \mathrm{~kg}$. 血圧 $70 / 45$ $\mathrm{mmHg}$, 心拍数 $92 / \mathrm{min}$. 体温 37.6 度, GCS 3-5-6. 眼瞼 結膜には軽度の貧血を認め, 全身の冷汗著明で, 臍周囲に 著明な自発痛を認めた。

血液検査所見 : WBC $13,400 / \mathrm{mm}^{3}, \mathrm{Hb} 11.6 \mathrm{~g} / \mathrm{dl}, \mathrm{BUN}$ $28.5 \mathrm{mg} / \mathrm{dl}$, Cr $0.92 \mathrm{mg} / \mathrm{dl}$, T-Bil $0.5 \mathrm{mg} / \mathrm{dl}$, ALB 2.7/dl, $\mathrm{CRP} 1.7 \mathrm{mg} / \mathrm{dl}$. 軽度の貧血と低アルブミン血症に加え, 白血球打よび炎症反応の上昇を認めた。

腹部造影 $\mathrm{CT}$ 検査 : 腹部人工血管中枢側吻合部において 前方に突出する仮性動脈瘤を認め, これが十二指腸水平脚 を圧排していた (図 1)。回腸終末から上行結腸にかけて 腸管内に造影剂の漏出があり，腹部大動脈十二指腸瘻によ る SAEF と診断した.

入院後経過打よび手術：当院搬入後，数回にわたり吐血 した. 出血性ショック状態であり, ICU 収容後に挿管, 全身管理を開始した。全身状態からは開腹手術に対する耐 術能は乏しいと判断した。出血性ショックからの離脱のた め，まずEVARを行い，その後全身状態が落ち着きしだ い，二期的手術を行う方針とした。

入院当日，全身麻酔下に手術を施行した。左大腿動脈よ りアクセスし，透視下に両側腎動脈入口部を確認しつつ,
瘻孔部を十分に覆うようにZenith ステントグラフト（Extension body $26 \mathrm{~mm}$, Cook Inc., Bloomington, IN, USA) を 留置した。将来的な migration が懸念されたため, 1 ステ ント分がオーバーラップするように末梢側に同サイズのス テントグラフトを重ねて留置した。術中造影にてエンド リークを認めず，瘦孔部からの oozing もないことを確認 して手術を終了した（図2)。

手術翌日, 出血性ショックから離脱して循環動態も安定 していたので，瘻孔処置を行うことにした．腹部正中小切 開下に十二指腸水平脚を同定した。周囲は癒着高度であっ たが，膿瘍形成は認めなかった。十二指腸水平脚を腹側か ら長軸方向に切開したところ直下に直径約 $1 \mathrm{~mm}$ の瘻孔部 を確認した。同部位は 2 層に縫合閉鎖し，同時に一時的空 腸瘻を造設した。術後も全身状態は安定しており，術後 2 時間で人工呼吸器から離脱できた。

入院時血液培養は陰性であったが, 腸管瘦による人工血 管感染の存在が疑われたため, 入院当日より cefmetazole $1 \mathrm{~g} /$ day + amikacin sulfate $800 \mathrm{mg} /$ day を投与開始した。抗 生剂開始後は順調に炎症反応の改善が得られ, 第 12 病日 の血液検査で WBC $7,100 / \mathrm{mm}^{3}, \mathrm{CRP} 0.3 \mathrm{mg} / \mathrm{dl}$ と炎症反 応正常化を確認して投与を終了した。術後第 14 病日より 


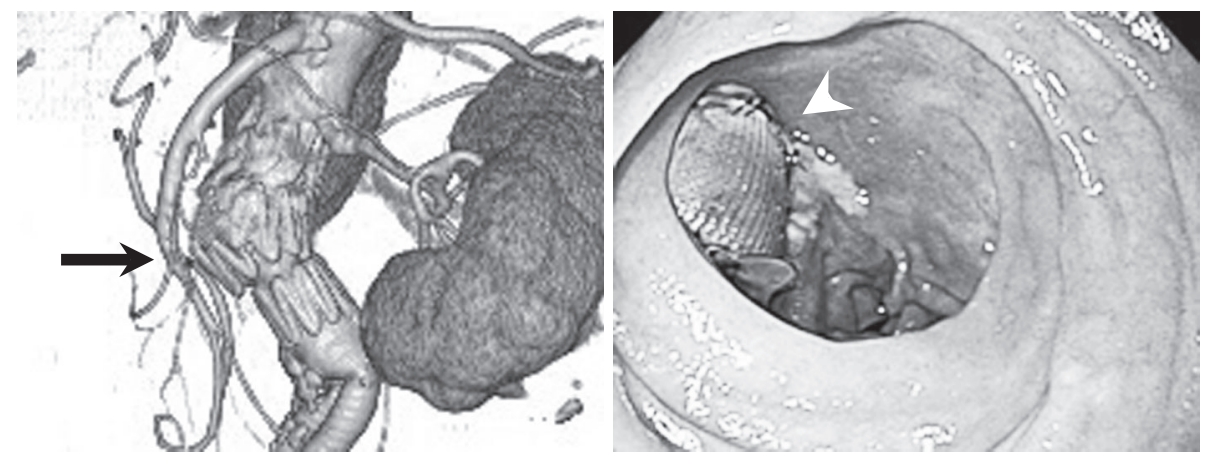

图 3 SAEF 再発時 CT 打よび上部消化管内視鏡検査

留置したステントグラフトは腹側へ変移し (矢印), 十二指腸水平脚では腸管内部より人 工血管露出を確認した (矢頭).

経腸栄養を開始し, 第 21 病日ガストログラフィン造影で 腸管外漏出のないことを確認した。空腸廔を抜去して経口 摂取を開始し，第 34 病日独歩退院となった。

退院後も造影 CT 検查で再発を認めず，血液検査所見で も感染徴候なく経過していたが, 術後 16 力月目, 自宅に て腹痛を自覚, 約 4 時間後に吐血を認め, 再度当院に救急 搬送された。造影 CT 検查では, 腎動脈直下に留置してい たステントグラフトの末梢側が腹側に突出するかたちで migration しており，十二指腸水平脚を圧排していた．緊 急内視鏡検査では，同部位にて十二指腸内腔に人工血管の 露出を確認した (図 3). 入院時血液検査では WBC $21,000 / \mathrm{mm}^{3}$ (Neutr 70.5\%)，CRP $2.75 \mathrm{mg} / \mathrm{dl}$ と炎症反応を 認めた。敗血症性ショックによる不安定な全身状態のた め，まず損傷した腸管を切除して人工血管周囲へ大網を充 填し, 状態が安定した時点で人工血管摘除と再置換術を行 う方針とした，腹腔内の癒着は高度であり，特に損傷した 十二指腸水平脚へのアプローチは困難であった。膵頭部を 含む周囲との癒着は非常に強固で, 腸管剝離中に複数の損 傷を生じたため, 膵頭十二指腸切除術が必要となった。人 工血管中枢側の出血はおさまっていたが，中枢側吻合部腹 側では人工血管に接するかたちで限局性の膿瘍貯留を認め た。 入院時血液培養は陰性であったが，術中培養ではグラ 么陽性球菌およびグラム陰性桿菌が検出された。デブリー ドメント後, 大網を充填して手術を終了したが, 術後も敗 血症コントロールは困難で, 術後第 11 病日に死亡した。

\section{考察}

腹部大動脈領域における SAEF は, 腹部大動脈術後 $0.3 \sim 1.6 \%$ の割合で発生する ${ }^{1)}$. SAEF の原因の一つは中枢 側吻合部仮性瘤であり，その発症率は $0.2 \sim 3.0 \%$ といわれ ている ${ }^{2,3)}$. 保存的治療では救命が困難なため, SAEF に対 しては外科的治療が必要である. 従来の SAEF に対する外 科的治療として感染創除去, 人工血管再置換術, 非解剖学
的バイパス術が行われてきたが，術後死亡率は依然として 高かった ${ }^{4 \sim 6)}$.こうした背景から最重症の SAEF は治療介 入が困難であったが，1999 年にDeshpande らが初めて SAEF に対する EVAR 治療例を報告して以来 ${ }^{7)}$, 開腹手術 が困難な重症の SAEF に対する EVARの報告が散見され るようになった。われわれが検索した範囲では, 腹部大動 脈領域の SAEF に対する EVAR の報告は 2000 年以降 46 例確認できた（表 1 ).

自験例では，初回搬入時の出血性ショックと併存症の問 題から EVARによる段階的治療の適応と考えた. 解剖学 的理由によるデバイスサイズの問題, および安全なランディ ングゾーン確保の観点から，2 本の extension body を用い てEVARを行う方針とした。出血コントロールにおいて EVAR は非常に効果的であり, 二期的に施行した空腸瘻造 設術後の経過も良好であったため, そのまま外来にて経過 観察としていた。しかし最終的な問題点はグラフト感染と SAEF 再発であった. SAEF 再発時には腹痛，吐血を生じ て救急搬送となったが, 直前までは再発の予兆となる身体 所見の異常は自覚していなかった. SAEF 再発時の開腹所 見では, 膿瘍は人工血管に接していたことから, 経過中は 表面化しなかった潜在的なグラフト感染の存在が示唆され た。膿瘍形成領域は組織が脆弱化したため, 同部位に向け て migration が生じ, 最終的にSAEF 再発に繋がったもの と考えられた。抗生剤投与期間も重要な問題点であった。 自験例では EVAR 後の炎症反応正常化を受けて投与終了, その後も通常の動脈瘤術後経過と大差なく炎症反応の上昇 は軽度に留まった。術後抗生郕投与期間に関する一定の consensus は得られていないが ${ }^{4,89}$, 潜在するグラフト感 染のリスクを十分考慮すれば終生投与が妥当であったと考 えられる. 一方で, 炎症後の癒着も再発後の治療を困難に させた一因であった. EVAR直後には小開腹から十二指腸 瘦孔部位を直接確認できたが, 再発時には上部腹腔内藏器 から後腹膜にかけて広範囲で強固な癒着があり,このため 
表 1 腹部大動脈領域の SAEF に対する EVAR 報告例（2000 年から 2011 年）

\begin{tabular}{|c|c|c|c|c|c|c|c|}
\hline 報告者（報告年） & $\begin{array}{l}\text { 年齢 } \\
\text { (歳) }\end{array}$ & 性別 & $\begin{array}{l}\text { Interval }^{*} \\
\text { (年) }\end{array}$ & 手術 & $\begin{array}{c}\text { 観察期間 } \\
\text { (月) }\end{array}$ & $\begin{array}{c}\text { 感染継続 } \\
\text { /再燃 }\end{array}$ & 死亡原因 \\
\hline Chuter et al. $(2000)^{27)}$ & 76 & $\mathrm{M}$ & 10 & SG $\rightarrow$ 初回人工血管摘除 & 8 & - & - \\
\hline Grabs et al. $(2000)^{29)}$ & 67 & M & 15 & SG+drainage & 18 & - & - \\
\hline Schlensak et al. $(2000)^{28)}$ & 64 & $\mathrm{M}$ & 16 & SG $\rightarrow$ 初回人工血管摘除 & 5 & - & - \\
\hline \multirow[t]{4}{*}{ Burks et al. $(2001)^{26)}$} & 92 & M & 12 & SG & 34 & - & - \\
\hline & 88 & $\mathrm{M}$ & 8 & SG+drainage & 11 & + & 敗血症 \\
\hline & 73 & $\mathrm{M}$ & 9 & SG+腸瘻造設 & 18 & + & CVA \\
\hline & 73 & $\mathrm{~F}$ & 5 & SG & 23 & - & - \\
\hline Dieter et al. $(2002)^{25)}$ & 64 & M & - & $\mathrm{SG} \rightarrow$ 初回人工血管摘除 & 3 & - & - \\
\hline Tomlinson et al. $(2002)^{24)}$ & 90 & $\mathrm{M}$ & 5 & SG & 14 & + & - \\
\hline González-Fajardo et al. (2005) ${ }^{12}$ & 75 & $\mathrm{M}$ & 5 & SG+腸管切除術 & 2 & + & 大動脈破裂 \\
\hline Suzuki et al. $(2005)^{3)}$ & 71 & $\mathrm{M}$ & 5 & SG & 20 & - & - \\
\hline Shapiro et al. $(2006)^{21)}$ & 83 & $\mathrm{~F}$ & 14 & SG & 14 & - & - \\
\hline Kotsis et al. $(2006)^{22)}$ & 53 & M & - & SG & 18 & + & - \\
\hline Biancari et al. $\quad(2006)^{20)}$ & 58 & M & 9 & SG+腸管切除術 & 8 & - & - \\
\hline \multirow[t]{11}{*}{ Danneels et al. $(2006)^{4)}$} & 49 & M & 5 & SG $\rightarrow$ 初回人工血管摘除 & 7 & + & - \\
\hline & 71 & $\mathrm{M}$ & 12 & SG & 12 & - & 肺癌 \\
\hline & 76 & $\mathrm{M}$ & 26 & SG $\rightarrow$ 初回人工血管摘除 & 21 & + & - \\
\hline & 70 & M & 5 & $\mathrm{SG}+$ drainage & 5 & + & - \\
\hline & 73 & M & 16 & SG $\rightarrow$ 初回人工血管摘除 & 33 & + & 敗血症，MOF \\
\hline & 61 & M & 7 & SG+非解剖学的バイパス術 & 1 & - & - \\
\hline & 78 & M & 4 & SG+腸管切除術 & 44 & - & - \\
\hline & 75 & $\mathrm{M}$ & 11 & 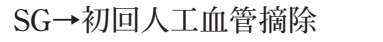 & 20 & + & - \\
\hline & 81 & $\mathrm{M}$ & 8 & SG+非解剖学的バイパス術 & 1 & - & - \\
\hline & 73 & $\mathrm{~F}$ & 5 & SG $\rightarrow$ 初回人工血管摘除 & 12 & + & $\mathrm{AEF}$ 再発, 出血 \\
\hline & 43 & $\mathrm{~F}$ & 3 & $\mathrm{SG}+$ drainage & 9 & + & - \\
\hline \multirow[t]{2}{*}{ Ascoli Marchetti et al. (2007) ${ }^{11)}$} & 76 & M & 0 & SG & 6 & - & - \\
\hline & 68 & $\mathrm{M}$ & 5 & SG $\rightarrow$ 初回人工血管摘除 & 2 & + & - \\
\hline Brountzos et al. $(2007)^{17)}$ & 85 & $\mathrm{M}$ & 10 & SG & 12 & + & - \\
\hline Chisci et al. $(2007)^{19)}$ & 56 & $\mathrm{M}$ & - & SG－初回人工血管摘除 & 6 & - & - \\
\hline \multirow[t]{2}{*}{ Bianchi et al. $(2007)^{18)}$} & 57 & M & 5 & SG $\rightarrow$ 初回人工血管摘除 & 0 & - & - \\
\hline & 76 & $\mathrm{M}$ & 24 & SG－初回人工血管摘除 & 0 & - & - \\
\hline \multirow[t]{5}{*}{ El Sakka et al. $(2008)^{16)}$} & 69 & M & 3 & SG & 0 & + & MOF \\
\hline & 73 & M & 4 & SG & 6 & + & 肺炎 \\
\hline & 67 & $\mathrm{M}$ & 0 & SG & 28 & + & - \\
\hline & 74 & $\mathrm{M}$ & 6 & SG & 27 & + & - \\
\hline & 78 & $\mathrm{M}$ & 3 & SG & 32 & + & 不詳 \\
\hline \multirow[t]{3}{*}{ Lindblad et al. $(2008)^{9)}$} & - & $\mathrm{M}$ & - & SG & 0 (0日) & - & 出血（術中） \\
\hline & - & M & - & SG & - & - & 敗血症, 出血 \\
\hline & 77 & $\mathrm{~F}$ & - & SG & 36 & - & - \\
\hline Leonhardt et al. $(2008)^{8)}$ & 82 & M & 6 & SG $\rightarrow$ 初回人工血管摘除 & 0 (3 日) & + & MOF \\
\hline Roche-Nagle et al. $(2009)^{14)}$ & 79 & $\mathrm{M}$ & - & SG & 0 & - & - \\
\hline Antoniadis et al. $(2009)^{15)}$ & 76 & $\mathrm{M}$ & - & SG+腸瘻造設術 & 4 & - & - \\
\hline Lee et al. $(2010)^{13)}$ & 72 & M & 4 & SG $\rightarrow$ 初回人工血管摘除 & 48 & + & - \\
\hline \multirow[t]{3}{*}{ Batt et al. $(2011)^{2)}$} & - & M & - & SG & 6 & + & $\begin{array}{l}\text { 敗血症, グラフト } \\
\text { 閉塞 }\end{array}$ \\
\hline & - & M & - & SG & 8 & + & $\mathrm{AEF}$ 再発 \\
\hline & 78 & $\mathrm{M}$ & - & SG & 0 (1日) & + & 心筋梗塞 \\
\hline
\end{tabular}

*初回人工血管置換術から $\mathrm{SAEF}$ 発症までの期間. SG, stent-grafting; MOF, multiple organ failure; AEF, aortoenteric fistula; CVA, cerebrovascular accident.

全身状態の悪いなかで侵襲の大きな術式を選択せざるを得 なかった。また，EVAR 直後の開腹手術では，十分な切開 の元で大網充填により感染巣拡大を抑える必要性を考慮し たが，術前の全身状態から手術侵襲を最小限に抑えること
を重要視したため小開腹手術を選択した。このため上腹部 に癒着した大網の剝離, 充填が困難となり, SAEF 再発の 一因になった可能性は否定できない。

SAEFに対してEVARを施行した自験例を含む 47 
例 2 6,8 29) のうち，根治術まで到達したのは 13 例であっ た. EVAR 単独治療は 21 例であり, 治療の第一段階のま ま経過観察される症例が約半数であった. EVAR 治療後の グラフト感染に対する懸念はこれまで多く報告されてき た ${ }^{2,5,7,11)} .47$ 例中死亡症例は 16 例認められたが, SAEF 関連死は 11 例であり, グラフト感染死は少なくとも 6 例 に認められた. SAEF 再発が直接原因であったものは自験 例を含めても 3 例のみであり, いずれも再発時に敗血症を 呈していた。また, SAEF 関連死のうち, EVAR 施行後 1 カ月以降の死亡例は 7 例であったが，5例では根治術が施 行されていなかった。遠隔期 SAEF 関連死を考慮した場 合, EVAR 単独で治療を完結することの危険性は高いこと が示唆される結果であった。感染巣と成り得る既存人工血 管を切除しない限りは将来的なグラフト感染のリスクから 解放されることはなく $4,6,11$, 遠隔期の SAEF 関連死を減ら すためには, 開腹手術が許容できる症例に対して積極的に 根治術を目指す必要性があると考えられた。

根治術施行の至適時期については一定の見解はいまだ得 られていない ${ }^{3,6)}$. EVARの進歩は著しいものの, EVAR 単 独治療では遠隔期グラフト感染のリスクは依然として払拭 できない. 自験例においても, 感染が成立する前段階で可 能な限り早期の根治術を行う必要があったと反省せざるを 得ない. EVAR 単独治療の限界を認識したうえで根治術の 至適時期を積極的に模索することが，今後の EVARの発 展には不可欠であると考える. SAEF 発症後, 急性期治療 の第一段階として EVAR を導入することで, 比較的低侵 襲に出血コントロールが期待できる. 血行動態が安定した うえで開腹手術が可能になれば，急性期における二期的根 治の可能性も広がり, EVAR 導入は治療戦略上さらに重要 な選択肢と成り得るものと考えられた。

\section{結 語}

SAEF に対する EVAR は急性期出血コントロールに有効 である。しかし，SAEF 関連死を予防するためには，可能 な限り早期に開腹手術による根治術を行うことが重要であ る.

\section{文献}

1) Kuestner, L.M., Reilly, L.M., Jicha, D.L. et al. : Secondary aortoenteric fistula: Contemporary outcome with use of extraanatomic bypass and infected graft excision. J. Vasc. Surg. 21 : 184-196, 1995.

2) Batt, M., Jean-Baptiste, E., O'Connor, S. et al. : Early and late results of contemporary management of 37 secondary aortoenteric fistulae. Eur. J. Vasc. Endovasc. Surg. 41 : 748757, 2011.

3) Suzuki, S., Imoto, K., Uchida, K. et al. : Endovascular repair of a presumed aortoduodenal fistula. Ann. Thorac. Cardiovasc. Surg. 11 : 424-428, 2005.
4) Danneels, M.I., Verhagen, H.J., Teijink, J.A. et al. : Endovascular repair for aorto-enteric fistula: A bridge too far or a bridge to surgery ?. Eur. J. Endovasc. Surg. 32 : 27-33, 2006.

5) Lonn, L., Dias, N., Veith Schroeder, T. et al. : Is EVAR the treatment of choice for aortoenteric fistula?. J. Cardiovasc. Surg. 51 : 319-327, 2010.

6) Kakkos, S.K., Antoniadis, P.N., Klonaris, C.N. et al. : Open or endovascular repair of aortoenteric fistulas?. A multicentre comparative study. Eur. J. Vasc. Endovasc. Surg. 41 : 625634, 2011.

7) Deshpande, A., Lovelock, M., Mossop, P. et al. : Endovascular repair of an aortoenteric fistula in a high-risk patient. J. Endovasc. Surg. 6 : 379-384, 1999.

8) Leonhardt, H., Mellander, S., Snygg, J. et al. : Endovascular management of acute bleeding arterioenteric fistulas. Cardiovasc. Interv. Radiol. 31 : 542-549, 2008.

9) Lindblad, B., Holst, J., Kölbel, T. et al. : What to do when evidence is lacking-implications on treatment of aortic ulcers, pseudoaneurysms and aorto-enteric fistulae. Scand. J. Surg. 97 : 165-173, 2008.

10) Antoniou, G.A., Koutsias, S., Antoniou, S.A. et al. : Outcome after endovascular stent graft repair of aortoenteric fistula : A systematic review. J. Vasc. Surg. 49 : 782-789, 2009.

11) Ascoli Marchetti, A., Gandini, R., Ippoliti, A. et al. : The endovascular management of open aortic surgery complications with emergency stent-graft repair in high-risk patients. J. Cardiovasc. Surg. 48 : 315-321, 2007.

12) González-Fajardo, J.A., Gutiérrez, V., Martín-Pedrosa, M. et al. : Endovascular repair in the presence of aortic infection. Ann. Vasc. Surg. 19: 94-98, 2005.

13) Lee, B. and Gutherz Neschis, D. : Late-term complication of endograft repair for aortoenteric fistula. Vasc. Endovasc. Surg. 44 : 395-398, 2010.

14) Roche-Nagle, G. and Oreopolous, G. : Endovascular treatment of a bleeding secondary aortoenteric fistula in a highrisk patient. Am. J. Emerg. Med. 27 : 374. e3-374. e5, 2009.

15) Antoniadis, P., Geropapas, G., Kounougeri, E. et al. : Acutely bleeding aortoduodenal fistula: Staged endovascular and open surgical repair. Vascular 17 : 197-200, 2009.

16) El Sakka, K., Halawa, M., Kotze, C. et al. : Complication of open abdominal aortic surgery: The endovascular solution. Interact. Cardiovasc. Thorac. Surg. $7:$ 124-125, 2008.

17) Brountzos, E.N., Vasdekis, S., Kostopanafiotou, G. et al. : Endovascular treatment of a bleeding secondary aortoenteric fistula. A case report with 1-year follow-up. Cardiovasc. Intervent. Radiol. 30 : 1037-1041, 2007.

18) Bianchi, P., Dalainas, I., Ramponi, F. et al. : Late gastrointestinal bleeding after infrarenal aortic grafting:A 16-year experience. Surg. Today 37 : 1053-1059, 2007.

19) Chisci, E., de Donato, G., Setacci, F. et al. : Recurrent aortoenteric fistula : Two different bridge solutions. Vascular 15 : 235-237, 2007.

20) Biancari, F., Romsi, P., Perälä, J. et al. : Staged endovascular stent-grafting and surgical treatment of a secondary aortoduodenal fistula. Eur. J. Vasc. Endovasc. Surg. 31 : 42-43, 2006.

21) Shapiro, M., Addis, M.D., Ellozy, S.H. et al. : Successful endovascular treatment of bleeding aortoenteric fistula: A case report. Ann. Vasc. Surg. 20 : 817-819, 2006.

22) Kotsis, T., Lioupis, C., Tzanis, A. et al. : Endovascular repair of a bleeding secondary aortoenteric fistula with acute leg ischemia : A case report and review of the literature. J. Vasc. Interv. Radiol. 17 : 563-567, 2006.

23) Dorigo, W., Pulli, R., Azas, L. et al. : Early and long-term 
results of conventional surgical treatment of secondary aortoenteric fistula. Eur. J. Vasc. Endovasc. Surg. 26 : 512-518, 2003.

24) Tomlinson, M.A., Gold, B., Thomas, M.H. et al. : Endovascular stent graft repair of a recurrent aorto-enteric fistula. Eur. J. Vasc. Endvasc. Surg. 24 : 459-461, 2002.

25) Dieter, R.A. Jr., Blum, A.S., Pozen, T.J. et al. : Endovascular repair of aortojejunal fistula. Int. Surg. 87 : 83-86, 2002.

26) Burks, J.A. Jr., Faries, P.L., Gravereaux, E.C. et al. : Endovascular repair of bleeding aortoenteric fistula: A 5year experience. J. Vasc. Surg. 34 : 1055-1059, 2001.
27) Chuter, T.A., Lukaszewicz, G.C., Reilly, L.M. et al. : Endovascular repair of a presumed aortoenteric fistula : Late failure due to recurrent infection. J. Endovasc. Ther. 7 : 240-244, 2000.

28) Schlensak, C., Doenst, T., Spillner, G. et al. : Palliative treatment of a secondary aortoduodenal fistula by stent-graft placement. Thorac. Cardiovasc. Surg. $48:$ 41-42, 2000.

29) Grabs, A.J., Irvine, C.D., Lusby, R.J. et al. : Stent-graft treatment for bleeding from a presumed aortoenteric fistula. J. Endovasc. Ther. 7 : 236-239, 2000. 